\title{
Wastewater dephosphorization using crude clays
}

\author{
${ }^{1}$ P. J. M. R. Dable; ${ }^{1} Y$. J. Adjoumani; ${ }^{2}$ B. Yao; ${ }^{2 *} G$. Ado \\ ${ }^{1}$ Laboratoire de Traitement de Surface, des Procédés et Mécanique des Matériaux, BP 1093 Yamoussoukro, Côte d'Ivoire \\ ${ }^{2}$ Laboratoire de Procédés Industriels de Synthèse et de l'Environnement, BP 1093 Yamoussoukro, Côte d'Ivoire
}

Received 4 November 2007; revised 26 November 2007; accepted 2 December 2007; available online 26 December 2007

\begin{abstract}
The present work aims to establish the possibility of using local clays to treat wastewater. Thus, three clay samples extracted from two localities in the south of Côte d'Ivoire have been studied in their crude state. The qualitative physicochemical study that consisted in measurement of $\mathrm{pH}$ variation and argillaceous particles zeta potential showed that the Nieki-Agneby clay and the Beige Anyama clay presented disposal to uptake phosphate ions in solution at $\mathrm{pH}$ 5. For each clay, it is shown that the tension accompanying the sorption of a phosphate ion could be estimated to $-5 \mathrm{mV}$. Differences in their composition and in the number of hydrating molecules of water were also accessible. The quantitative study performed with the Nieki-Agneby clay thereafter consisted following the sorption kinetic. The adsorption was found to reach the maximum after $5 \mathrm{~h}$. of exchange, and almost $400 \mu \mathrm{g}$ phosphate ions in per gram of clay were fixed. Future studies will focus on the modification of these materials in order to increase their sorption capacity.
\end{abstract}

Key words: Clay, dephosphorization, pH, zeta potential, sorption, kinetic study

\section{INTRODUCTION}

Industrial and individual activities generate wastewater that contains pollutants which are mostly consisted of nitrate and phosphate components (Barroin, 1980). It is well-known that the latter component is one of the principal factors responsible for the surface water eutrophication. Thus, in order to limit this phenomenon, wastewaters needed to be dephosphorized before rejection in the environment.

Phosphorus does not exist in free form. It is always combined with other chemical elements. In wastewaters, phosphorus is mainly in the form of orthophosphate $\left(\mathrm{H}_{\mathrm{x}} \mathrm{PO}_{4}{ }^{\mathrm{x}-3}\right)$, or polyphosphate (polymer of the phosphoric acid) and organic phosphorus fixed by the bacteria (Mollé, 2004). However, because of hydrolysis reactions, the two last ones disappear and only the orthophosphate prevails in solution. The phosphate ion can be in three states of equilibrium:

$$
\begin{aligned}
& \mathrm{H}_{3} \mathrm{PO}_{4}+\mathrm{H}_{2} \mathrm{O} \rightleftharpoons \mathrm{H}_{2} \mathrm{PO}_{4}^{-}+\mathrm{H}_{3} \mathrm{O}^{+} \\
& \mathrm{H}_{2} \mathrm{PO}_{4}^{-}+\mathrm{H}_{2} \mathrm{O} \rightleftharpoons \mathrm{HPO}_{4}^{2-}+\mathrm{H}_{3} \mathrm{O}^{+} \\
& \mathrm{HPO}_{4}{ }^{2-}+\mathrm{H}_{2} \mathrm{O} \rightleftharpoons \mathrm{PO}_{4}^{3-}+\mathrm{H}_{3} \mathrm{O}^{+}
\end{aligned}
$$

The values of the acidity constants are 2.1, 7.2 and

\*Corresponding Author Email: beyao@yahoo.fr

Tel.:+225 078005 19; Fax: +225 30640406
12.5, respectively. The complexes are formed with divalent or trivalent cations and become significant according to the $\mathrm{pH}$ (Mollé, 2004). Phosphate ions are eliminated from water only in solid form. The chemical elimination (Memotec, 2004) consists in a reaction with cationic species to form solid phases that precipitate. Clay is defined as a rock mainly constituted of silicates in layers (aluminum phyllosilicates) more or less hydrated with particle sizes lower than $2 \mu \mathrm{m}$. Many studies concerning clays were reported (Özacar and Sengil, 2003; Gimsing; et al., 2007; Violante; et al., 2002; Callère, et al., 1982 and 1989; Castelein, 2000; Holtzapffel, 1985). The argillaceous mineral terms or phyllites are devoted to them. The basic structure of phyllitious silicates, as all silicates, is the $\mathrm{SiO}_{4}^{4}$ ion in which the $\mathrm{Si}^{4+}$ silicon ion is tetra coordinated to the $\mathrm{O}^{2-}$ ions. The aluminum $\mathrm{Al}^{3+}$ ion that can also be tetra coordinated and thus is able to play the same role to $\mathrm{Si}^{4+}$ substitutes this ion to give an aluminous silicate. However, $\mathrm{Al}^{3+}$ is generally hexa coordinated to the ion oxygenate $\mathrm{O}^{2-}$ or the ion hydroxide $\mathrm{OH}^{-}$. This variation of coordination is due to the ratio of the ionic radius $\mathrm{Al}^{3+} / \mathrm{O}^{2-}$ which is worth 0.430 : the border value between co-ordination number 4 (tetrahedral) and co-ordination number 6 (octahedral), (Castelein, 2000). 
Attention was then made by the results of the investigations carried out on some clay samples of the site of Gounioube in Côte d'Ivoire (Abba, et al., 2001). The chemical analyses revealed that these samples contained phosphorus oxide $\left(\mathrm{P}_{2} \mathrm{O}_{5}\right)$ in the proportions ranging from 0.35 to $1.09 \%$. This fact lets foresee a probable capacity of these clays to fix phosphorus. In this probable case, this abundant and easily accessible material could be used for phosphorus elimination from wastewater.

To begin with, the physico-chemical qualitative aspects that can tighten this dephosphorization were established. Then, a quantitative approach made it possible to establish the kinetic of this process. The phosphorus mass fixed per unit of clay mass and the duration time to be reached for equilibrium between sorption and desorption were determined.

\section{MATERIALS AND METHODS}

Three clays extract in 2005 from three different sites of the south of Côte d'Ivoire were used. The first from the Nieki-Agneby site in the locality of Dabou presented a grey color. This clay was called NAC to indicate Nieki-Agneby clay. The two other samples were from two sites in the locality of Anyama. One of these that presented a green coloration was identified as Green Anyama clay and noted as GAC and the last one of beige colorless was identified as Beige Anyama clay and noted as BAC. All the samples were taken in argillaceous layers from 0.5 to $1 \mathrm{~m}$. depth.

The $\mathrm{pH}$ measurement was performed by using a pH-meter of the standard pH M210 Meterlab of Tacussel-Electronic. For the clays acidity determination, $5 \mathrm{~g}$ of each were spanned out in $25 \mathrm{~mL}$ of distilled water by stirring during $10 \mathrm{~min}$. and left to dismiss. Then, the $\mathrm{pH}$ value of the supernatant liquid was measured. The main experimentation was undertaken as follows: for each type of clay, solutions of $5 \mathrm{~g} / \mathrm{L}$ containing $0.2 \mathrm{~g}$ of $\mathrm{KH}_{2} \mathrm{PO}_{4}$ were prepared. These solutions were then disposed in seven containers and carried to the values of $\mathrm{pH}$ from 3 to 6 , using a chlohydric acid solution and adjusted with a solution of sodium hydroxide.

The samples were maintained under agitation during $48 \mathrm{~h}$. and left to sediment for about $24 \mathrm{~h}$. and the supernatant liquid $\mathrm{pH}$ was measured.

The particle charges were determined by measurement of their zeta potential using a Zetasizer 3000 HS. This apparatus measures the potential of the colloidal particles by determining the deviation they undergo in a known electric field. This value represents the global charges that are present on their surface. The evolution of this value is necessarily related to the sorption of the chemical species on the surface of the clay particles which results in a variation of the zeta potential. In the case of the experiments here, a charge variation should imply a change of equilibrium between the active species present in the solution that are the phosphate ion, the protons, the hydroxides and the surface of the clay particles.

Parfitt indicates that from all the anions present in a solution, phosphate is the one that expresses greatest affinity for the ground components (Parfitt, 1978). The decreasing scale of affinity is:

arsenate $=$ phosphates $>$ seleniate $=$ molybdate $>$ sulphate $=$ fluoride $>$ chloride $>$ nitrate

Consequently, the appearance of negative charges would be primarily due to the fixing of the phosphate ions. If this is the case, these results should make it possible to identify the best clays for dephosphorization. The $\mathrm{pH}$ variation is expressed by:

$$
\Delta p H=p H_{f}-p H_{i}
$$

$\mathrm{pH}$ is the difference between the $\mathrm{pH}$ after and before contact with the clays phase. This value should be permitted to approach the acid base reaction that accompanies the change of the particles charge. The simultaneous study of the $\mathrm{pH}$ variation and the surface charge evolution as a function of the initial $\mathrm{pH}$ should allow the description of the process and the determination of the $\mathrm{pH}$ values for which phosphate ions sorption is effective.

Tubes of $25 \mathrm{~mL}$ that previously contain $100 \mathrm{ppm}$ of $\mathrm{KH}_{2} \mathrm{PO}_{4}$ were brought to $\mathrm{pH} 4.5$ with a hydrochloric acid solution of $1 \mathrm{M}$. After adding $5 \mathrm{~g}$ of clay, the tubes were closed; then, they were placed on a device of agitation with controlled horizontal oscillation for a duration time ranging from $30 \mathrm{~min}$. to $7 \mathrm{~h}$. The samples were taken with intervals of well-defined times. After centrifugation and filtration, the solutions were prepared for analysis with an atomic absorption spectrophotometer-AA 20. The filtrates were collected in a graduated flask of $100 \mathrm{~mL}$. $1 \mathrm{~mL}$ of the filtrate was introduced into a tube of glass. $10 \mathrm{~mL}$ of concentrated sulfuric acid and catalyst made up of a mixture of selenium and sodium chloride powder in a mass ratio of 1:2 were added, respectively. Then, the melt was mineralized for $2 \mathrm{~h}$. The residue was collected in a 
graduated $100 \mathrm{~mL}$ flask and was brought back to the feature of gauge with distilled water. The mass of phosphorus adsorbed is determined by the following relation (Nuray, 1999):

$\mathrm{Q}=(C o-C) \frac{V}{m}$

where, $V$ is the volume of the solution used $(0.025 \mathrm{~L})$ and $\mathrm{m}$ is the mass of absorbent (5 g).

From a mother phosphate solution of $100 \mathrm{ppm}$ in content, a series of solution of known concentration was prepared by dilution. These samples were carried to the spectrometer for analysis. A calibration curve representing the absorbance according to the content phosphate is established based on the relation of Beerlambert:

$$
A=\varepsilon \ell c
$$

with $\varepsilon$ as the mass absorption coefficient, $l$ the length of the tank in $\mathrm{cm}$ and $C$, the concentration, in ppm. The phosphate contents of the samples worked out for the calibration are given starting from the formula of the following dilution:

$$
d=\frac{C_{i}}{C_{f}}=\frac{V_{f}}{V_{i}}
$$

with $d$ the factor of dilution, $\mathrm{C}_{\mathrm{i}}$ concentration of the initial solution, $V_{f}$ the volume of the samples which is $25 \mathrm{~mL}$ and the $V_{i}$ volume of the initial solution taken. The concentration $C_{f}$ of the diluted solution was then calculable starting from the expression of the factor of dilution $d$.

The linear regression coefficient $\mathrm{R}^{2}$ is equal to 1 . Thus, for each absorbance read, the corresponding phosphorus concentration was determined. Thus, the evolution of the remaining concentration $C$ and the evolution of the percentage of absorption according to time were plotted. The proportioning of phosphorus in the solutions was carried out by the method of indirect proportioning of the molybdate complexes (AFNOR, 1994).

\section{RESULTS AND DISCUSSION}

The prime test reveals the NAC to be the most alkali with a $\mathrm{pH}$ of 6.8. Considering Fig. $1 \mathrm{a}$, an increase in the $\mathrm{pH}$ is noted, betraying the release of hydroxide ions in the medium which react with the protons to form water. The released hydroxide ions necessarily come from the clay particles. Alkali components such as $\mathrm{KOH}$ and $\mathrm{NaOH}$ may be present in this clay. Their dissolution in the water releases hydroxides, while the cationic ions that are badly solvated are spurned at the particles surface. This releasing hydroxide reaches its maximum for $\mathrm{pH}$ ranging between 4.5 and 5 . For higher $\mathrm{pH}$ values, the equilibrium state is close or reached, so the $\mathrm{pH}$ variation fails ( Fig. $1 \mathrm{a}$ ).

From the shape of the particles charge variation curve in Fig. $1 \mathrm{~b}$, one notes that they are negatively charged and this charge increases to reach a maximum value of $-36 \mathrm{mV}$ starting from $\mathrm{pH}$ 4.5. The particles thus present an excess of negative charges.

It is known that the ground components hydroxyl groups can be protonated in acidic solution loading them with positive charge (Chung, 1991; Martinez, 2001):

$$
\mathrm{R}-\mathrm{OH}+\mathrm{H}_{3} \mathrm{O}^{+} \rightleftharpoons \mathrm{R}-\mathrm{OH}_{2}^{+}+\mathrm{H}_{2} \mathrm{O}
$$

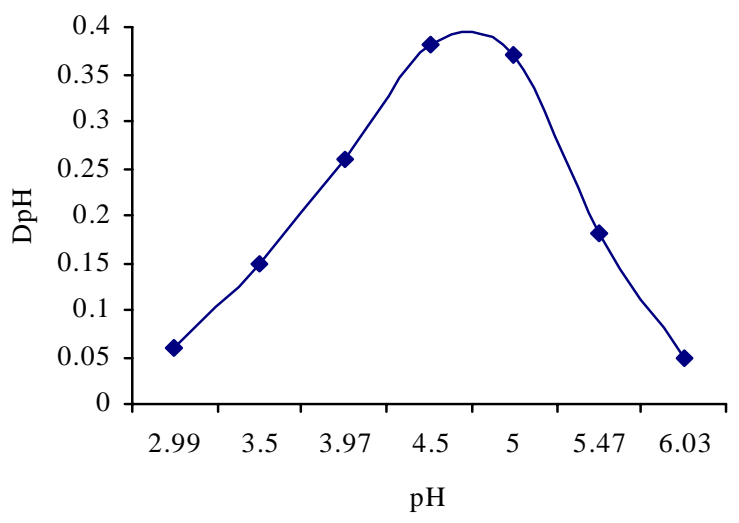

Fig. 1a: Variation of $\mathrm{pH}$ values for NAC samples

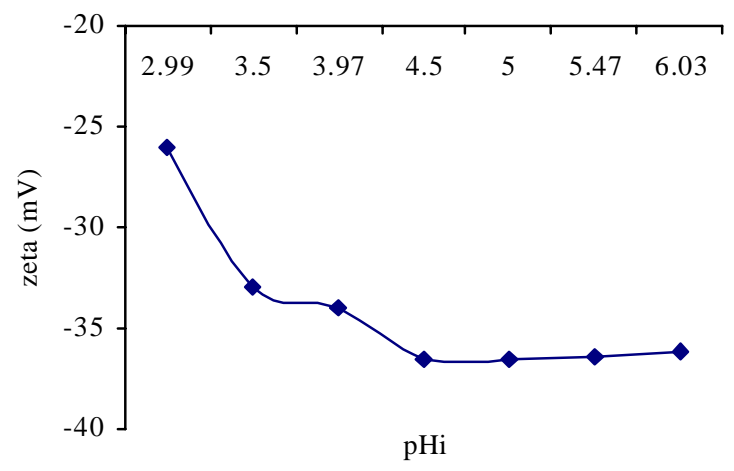

Fig. 1b: Zeta potential variation versus solution initial $\mathrm{pH}$ values for NAC 
Considering the particles zeta potentials values determined, the investigations were obviously undertaken in a range of $\mathrm{pH}$ beyond the $\mathrm{pH}$ of zero point charge (ZPC). For silica, the $\mathrm{pH}$ zero point charge stands around pH 2.5 (Yeh and Wan, 1994).

Thus, when clay is made of silicate ions, the $\mathrm{pH}$ of zero point charge must be closed to 2.5 so that the range of investigation evidently stands beyond.

At the $\mathrm{pH}$ of zero point charge, the particles present a neutral charge because of the adsorption of negatively charged species.

This sorption cannot be due to the hydroxide, since, in such a case, one would not note an increase in the $\mathrm{pH}$ and, in addition to it, the activity of hydroxide ions is very feeble on the considered $\mathrm{pH}$ range. By taking account of the species present in the solutions, only the phosphate ion is suitable to carry out this neutralization according to the following reaction pathway:

$$
\mathrm{S}-\mathrm{OH}_{2}^{+}+\mathrm{H}_{2} \mathrm{PO}_{4}^{-} \rightleftharpoons \mathrm{S}-\mathrm{OH}_{2}^{+}\left(\mathrm{H}_{2} \mathrm{PO}_{4}^{-}\right)
$$

with S pointing out the surface of the particle.

This electrostatic attraction can lead to a stable link form which would give a neutral molecule on the surface of $\mathrm{S}-\mathrm{PO}_{5} \mathrm{H}_{4}$.

Clays as all natural phases are made up at the base of aluminous silicate. In such phases, cationic metal of acidic nature such as $\mathrm{Al}^{3+}, \mathrm{Mn}^{3+}$ and $\mathrm{Fe}^{3+}$ are available in the form of ox hydroxide. These cationic ions by their flood acidity are likely to receive the doublets of oxygen from the phosphate ion via a specific sorption in their empty quantum boxes.

Consequently, this confers a negative charge to the clay particles and can be illustrated by Eq. 10 .

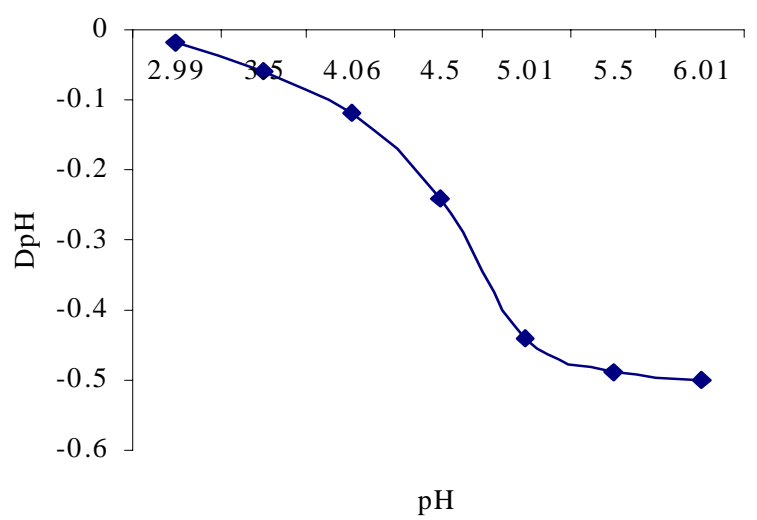

Fig. 2 a: Variation of $\mathrm{pH}$ values for GAC samples

$$
\begin{aligned}
& S-O-A l\left(\mathrm{OH}_{2}^{+}\right)_{2}+n H_{2} P_{4}^{-} \rightleftharpoons \\
& \left.S-O-A l\left(\mathrm{OH}_{2}^{+}\right)_{2} n H_{2} \mathrm{PO}_{4}^{-}\right]^{(n-2)}
\end{aligned}
$$

This would correspond to the species with - (n-2) charge linked to the particle surface. The increase of the phosphate ions sorption with the $\mathrm{pH}$ comes from an equilibrium state between the species $\mathrm{H}_{3} \mathrm{PO}_{4} / \mathrm{H}^{+}$ and $\mathrm{H}_{2} \mathrm{PO}_{4}^{-}$. This remains in agreement with the field of $\mathrm{H}_{2} \mathrm{PO}_{4}^{-}$prevalence which extends from $\mathrm{pH} 2.7$ to 7 and reaches its maximum activity around $\mathrm{pH} 4.5$. The constant of sorption noted for $-36 \mathrm{mV}$ indicates the saturation of all the sites susceptible to adsorb the phosphate ion which, in this range of $\mathrm{pH}$, present higher activity. The phosphate ions thus adsorbed remain fixed to the clay in the layer of STERN with a rather low energy level making the specific sorption connection stable.

The NAC so fixes phosphate ions and this remains in accordance with the conclusion of previous works on clays (Buol and Eswaran, 2000). These results underline that the NAC contains a lot of alkali components and metallic trivalent ox hydroxides which are likely to establish specific adsorption with phosphate ions.

In case of GAC and from Fig. 2 a, it is apparent that the solution becomes increasingly acidic. This indicates that the species on the surface of the clay particles induce reaction with the molecules of water to release protons. The chlorides, sulphates and nitrates show very weak affinity with ground components. Consequently, they are likely to be at the origin of the $\mathrm{pH}$ variation.

In the argillaceous phase, the metallic ions are related to the particle by a stable connection oxygenates/ion

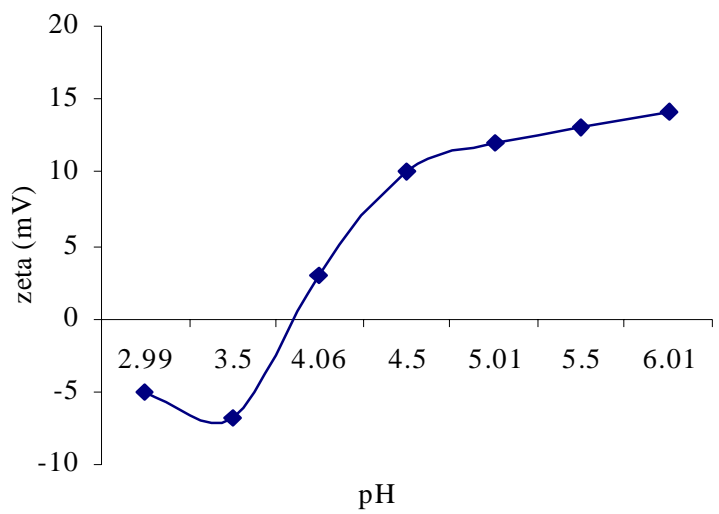

Fig. 2 b: Zeta potential variation versus solution initial $\mathrm{pH}$ values for GAC 
metal and can then be linked to any other kind of anions. The example of an aluminum cationic ion linked in the same time with nitrate and chloride ions is considered for illustration. Such species can arise as presented in Fig. 2 b.

The reaction that could cause the acidification of the medium intervenes as follows:

$$
\begin{aligned}
& \mathrm{S}-\mathrm{O}-\mathrm{Al}\left(\mathrm{Cl} ; \mathrm{NO}_{3}\right)+2 \mathrm{H}_{2} \mathrm{O} \rightleftharpoons \\
& \left.\mathrm{S}-\mathrm{O}-\mathrm{Al}^{2+} ; 2 \mathrm{OH}^{-}\right)+\mathrm{HNO}_{3}+\mathrm{HCl}
\end{aligned}
$$

The hydroxide ions remain on the clay particles where they probably form a metallic hydroxide with metallic ions such as $\mathrm{Na}^{+}, \mathrm{K}^{+}$or $\mathrm{Mg}^{2+}$ present on the particles surfaces.

The acidification increasing with the $\mathrm{pH}$ is due to the fact that in acidic medium, the activity of the basic form of water augments with $\mathrm{pH}$. Therefore, acidification may increase with $\mathrm{pH}$ according to reaction 5 .

The released acid forms would be responsible for the noted acidification of the solutions. The phosphate ions present in the solution are likely to be adsorbed via the free doublets of the oxygen molecules in the empty quantum boxes of the aluminum ion. Thus, the surface charge would be neutralized up to the point of $\mathrm{pH}$ with zero charge, which is again lower than the range of the $\mathrm{pH}$ investigated:

$$
\begin{gathered}
\left.\mathrm{S}-\mathrm{O}-\mathrm{Al}^{2+}\right)+n \mathrm{H}_{2} \mathrm{O}+2 \mathrm{H}_{2} \mathrm{PO}_{4}^{-} \rightleftharpoons \\
\left.\mathrm{S}-\mathrm{O}-\mathrm{Al}^{2+} ; 2 \mathrm{H}_{2} \mathrm{PO}_{4}^{-}\right)^{0} \mathrm{nH}_{2} \mathrm{O}
\end{gathered}
$$

Adsorption of the phosphate ions remains always effective until $\mathrm{pH}$ goes round 3.5 while conferring negative charge to the particles:

$$
\begin{aligned}
& \left.\mathrm{S}-\mathrm{O}-\mathrm{Al}^{2+} ; 2 \mathrm{H}_{2} \mathrm{PO}_{4}^{-}\right)^{0} \mathrm{nH}_{2} \mathrm{O}+\mathrm{H}_{2} \mathrm{PO}_{4}^{-} \rightleftharpoons \\
& \left.\mathrm{S}-\mathrm{O}-\mathrm{Al}^{2+} ; 3 \mathrm{H}_{2} \mathrm{PO}_{4}^{-}\right)^{-} \mathrm{nH}_{2} \mathrm{O}
\end{aligned}
$$

The phenomenon is, however, limited because of a probable steric obstruction due to the size of the phosphate ions and $\mathrm{n}$ molecules of water that are adsorbed by non-specific mode to aluminum ion.

When $\mathrm{pH}$ goes beyond $\mathrm{pH}$ 3.8, the particles become positive. Therefore, the phosphate ions are not any more adsorbed. Amongst other things, acidity marks a significant fall indicating a notable release of protons. Regarding to the composition of clays, this phase contains octahedral sites metallic ions, such as $\mathrm{Mg}^{2+}$, $\mathrm{Fe}^{3+}$ and $\mathrm{Al}^{3+}$. Those ions are characterized by a flood acidity that can cause acidification of the solution. For example, the ion $\mathrm{Al}^{3+}$ can be hydrolyzed and release protons that can cause a higher acidification according to the following reaction:

$\mathrm{Al}^{3+}+3 \mathrm{H}_{2} \mathrm{O} \rightleftharpoons \mathrm{Al}(\mathrm{OH})_{3(\text { solution })}+3 \mathrm{H}^{+}$

The releasing of metallic ions is well-known in earth sciences. The released aluminum ion is responsible for the alumino toxicity of soil (Fardeau and Zapata, 2002). The appearance of the positive charges on the particles then finds its origin in a protonation of the molecules of water, which hydrate the particles. The series of reactions that control the evolution of the positive charge would be related to the number of molecules of water adsorbed according to the following stages:

- Neutralization of negative charges for pH 3.8:

$$
\begin{aligned}
& \left.\mathrm{S}-\mathrm{O}-\mathrm{Al}^{2+} ; 3 \mathrm{H}_{2} \mathrm{PO}_{4}^{-}\right) \mathrm{nH}_{2} \mathrm{O}+\mathrm{H}^{+} \rightleftharpoons \\
& \left.\mathrm{S}-\mathrm{O}-\mathrm{Al}^{2+} ; 3 \mathrm{H}_{2} \mathrm{PO}_{4}^{-}\right)^{-} \mathrm{H}_{3} \mathrm{O}^{+}(n-1) \mathrm{H}_{2} \mathrm{O}
\end{aligned}
$$

- Appearance of positive charges:

$\left.\mathrm{S}-\mathrm{O}-\mathrm{Al}^{2+} ; 3 \mathrm{H}_{2} \mathrm{PO}_{4}^{-}\right)^{-} \mathrm{H}_{3} \mathrm{O}^{+}(\mathrm{n}-1) \mathrm{H}_{2} \mathrm{O}+\mathrm{H}^{+} \rightleftharpoons$

$\left.\mathrm{S}-\mathrm{O}-\mathrm{Al}^{2+} ; 3 \mathrm{H}_{2} \mathrm{PO}_{4}^{-}\right)^{-} 2 \mathrm{H}_{3} \mathrm{O}^{+}(n-2) \mathrm{H}_{2} \mathrm{O}$

The number of molecules of water adsorbed can be determined considering the surface charge evolution curve (Fig. 2 b). Indeed, if one takes the potential of negative surface charge of $-5 \mathrm{mV}$ as a unit in conformation with reaction 9 (where, neutralization stands between a negative and a positive charge), the difference between this charge and the plateau of the positive charge located at approximately $+15 \mathrm{mV}$ gives 4 as ratio. One would thus need 4 quantities of positive charge to find the potential of $+15 \mathrm{mV}$. Thus, protonation of four molecules of water is required, indicating the same way the number of molecule of water that ensures hydration of the particles.

Finally, The GAC does not present a good provision for phosphate ions elimination. When sorption is possible and $\mathrm{pH}$ goes round 3.5 only, the value of $-5 \mathrm{mV}$ reveals that very little adsorption takes place in contrary to the NAC which exhibits adsorption until $36 \mathrm{mV}$.

Fig. 3 a indicates that the solution evolutes being more acidic with a shape very close to Fig. 2 a but with a lower maximum of variation: -0.3 instead of -0.5 for the GAC. At the same time, the particles zeta potential evolution Fig. $3 \mathrm{~b}$ is closer to the NAC.

The acidification of the medium could find its explanation by the main process that stands with the 


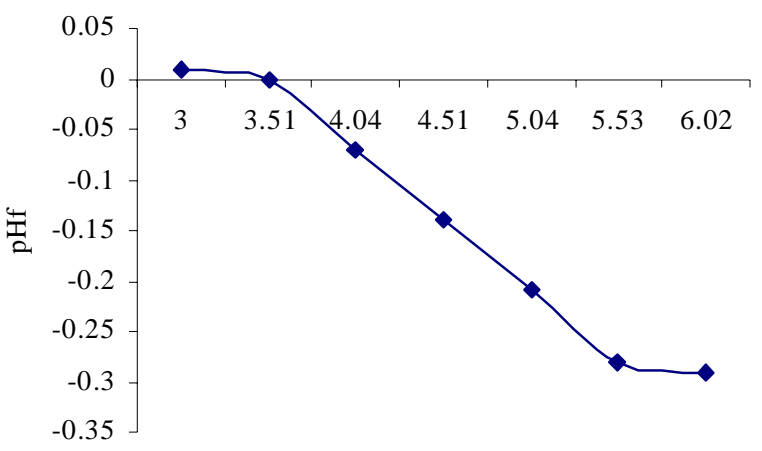

$\mathrm{pHi}$

Fig. 3 a: Variation of $\mathrm{pH}$ values for BAC samples

GAC sample illustrated by equation 8 . But simultaneously, the evolution of the charges lets foresee that this clay sample does not present high level of metallic acid ions which their release in the solution could cause higher acidification and the neutralization of the particles negative charges by the produced protons.

This is tightened by the results of the prime test that pulls out GAC samples to be more acidic than the BAC ones with pH values of 2.8 and 3.3, respectively. The adsorption that leads to $\mathrm{pH}$ of zero charge stands as follows:

$$
\begin{aligned}
& \left.\mathrm{S}-\mathrm{O}-\mathrm{Al}^{2+}\right) n \mathrm{H}_{2} \mathrm{O}+2 \mathrm{H}_{2} \mathrm{PO}_{4}^{-} \rightleftharpoons \\
& \left.\mathrm{S}-\mathrm{O}-\mathrm{Al}^{2+} ; 2 \mathrm{H}_{2} \mathrm{PO}_{4}^{-}\right)^{0}(n-2) \mathrm{H}_{2} \mathrm{O}
\end{aligned}
$$

The $n$ molecules of water are not specifically adsorbed to the empty quantum boxes of the ion aluminum. Thus, each specific adsorption of a phosphate ion induced the release of a molecule of water. Adsorption then reaches its maximum when all the molecules of water are desorbed:

$$
\begin{aligned}
& \left.\mathrm{S}-\mathrm{O}-\mathrm{Al}^{2+} ;(n-1) \mathrm{H}_{2} \mathrm{PO}_{4}^{-}\right)^{-(n-1)} \mathrm{H}_{2} \mathrm{O}+\mathrm{H}_{2} \mathrm{PO}_{4}^{-} \rightleftharpoons \\
& \left.\mathrm{S}-\mathrm{O}-\mathrm{Al}^{2+} ; n \mathrm{H}_{2} \mathrm{PO}_{4}^{-}\right)^{-(n-2)}+\mathrm{H}_{2} \mathrm{O}
\end{aligned}
$$

This process comfortably reduces the steric obstruction which supports the adsorption of the phosphate ions contrary to the case of GAC. It points out that the kinetic of hydronium ion formation by water protonation is more rapid than phosphate ion adsorption. Consequently, it seems that BAC presents provisions for elimination of the phosphate ions. By taking into account the assumption made previously according to which, a charge would be equivalent to -

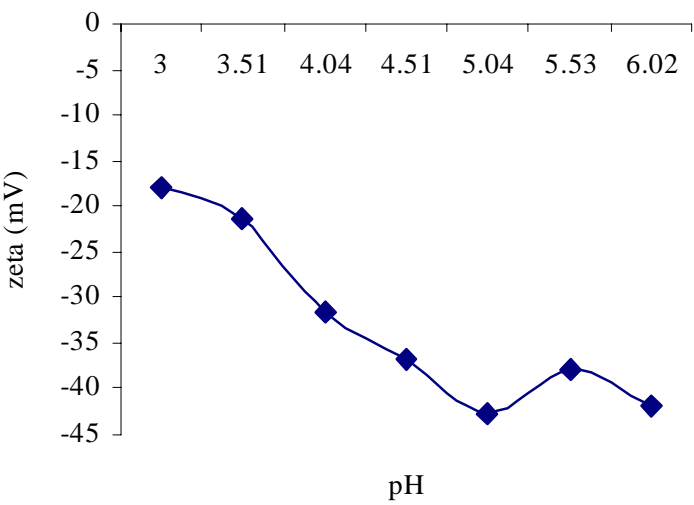

Fig. 3 b: Zeta potential variation versus solution initial $\mathrm{pH}$ values for BAC

$5 \mathrm{mV}$, the maximum of $-40 \mathrm{mV}$ reached would correspond to the adsorption of 8 phosphate ions.

This remains in agreement with the electronic structure of the ion $-\mathrm{Al}^{2+}$ considered with 8 quanta boxes free. So, hydration is ensured by 8 molecules of water. According to these considerations the tension variation of phosphate ion specific adsorption would be of $-5 \mathrm{mV}$. Considering reaction 7 for the NAC, the particle charges are given by -(n-2). The phosphate ions sorption reaches its optimum for $-36 \mathrm{mV}$. The specific sorption is assumed to require a tension variation of $-5 \mathrm{mV}$ and the calculation gives $\mathrm{n}$ equal to 7. Thus, hydration is ensured by 7 molecules of water for the NAC.

According to both samples presenting disposal for phosphate ions adsorption, the kinetic and quantitative approaches have been undertaken on the NiekiAgneby clay. Phosphorus adsorption rate as a function of the contact time is plotted in Fig. 4. It appears that a phosphorus adsorption reaches its maximum (about $80 \%$ ) after $4 \mathrm{~h}$. The value calculated for this experiment gives $400 \mu$ fixed per g of clay.

The objective of this study was to establish the capacity of phosphate ions sorption by different crude clays for wastewater dephosphorization. With this intention, the parameters which prove the effectiveness of adsorption made it possible to establish the capacities of dephosphorization of various clays. It implies to conclusion that the NAC and the BAC show such a disposal. The experimental results show that the adsorption which takes place is a specific one, ensuring a good dephosphorization. This study also establishes that dephosphorization takes place for a 


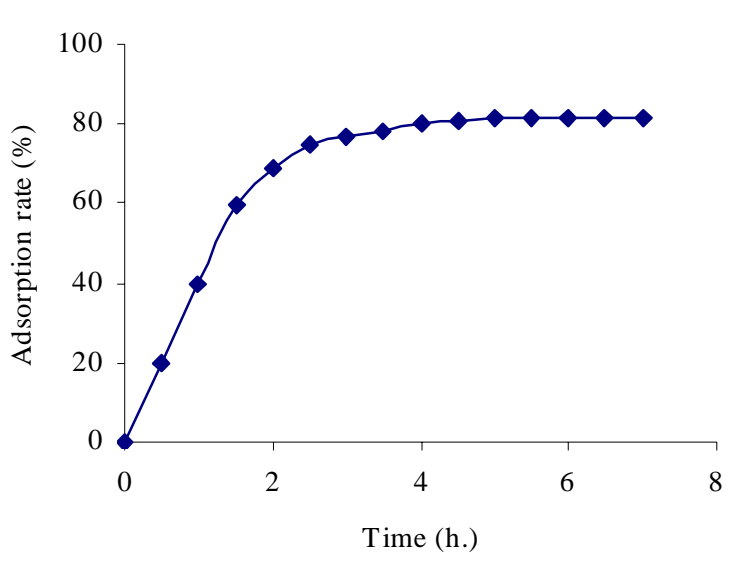

Fig. 4: Adsorption rate as a function of the time

value of $\mathrm{pH}$ compatible with the field of prevalence of the phosphate ion $\mathrm{H}_{2} \mathrm{PO}_{4}^{-}$.

Exploitation of the experimental results makes possible the determination of the number of molecule of water adsorbed on each kind of clay. At the same time, one has also pointed out a difference in a composition that obviously controls the phosphate sorption. Thereby, the NAC should be an alumino silicate containing alkali components and trivalent acid metallic ions. Its hydration is ensured by 7 molecules of water. The GAC and the BAC are respectively hydrated by 4 and 8 molecules of water and should contain anions of very low affinity with ground components: the first one also exhibiting a high level of acidic metallic ions. The quantitative study that has consisted in establishing the kinetics of sorption was undertaken. The results indicate that equilibrium with sorption and desorption is reached after $4 \mathrm{~h}$. corresponding to almost $400 \mu \mathrm{g}$ of phosphorus adsorbed per gram of the studied clay. The elimination of the phosphorus from wastewater by the NAC from the site of Dabou and the BAC is thus possible. Treatments and experimentations may be undertaken to improve these particularities in order to valorize these local materials. Such treatment should improve the duration time for the equilibrium to be reached and the quantity of the adsorbed phosphates ions.

\section{REFERENCES}

Abba, T.; Andji, J. Y. Y.; Sei, J.; Kra et, G.; Njopwouo, D., (2001). Caractérisation minéralogique de quelques échantillons d'argile du site de Gounioube (Côte d'Ivoire). J. Ouest. Afr. Soc. Chim, 11, 143-166.

AFNOR (1994). Qualité de l'eau : environnement. Association Française de Normalisation, NF T 90-023, Paris.

Barroin, G., (1980). Eutrophisation, pollution nutritionnelle et restauration des lacs. La pollution des eaux, P.Pesson édition Gauthier-Villard.

Buol, S. W.; Eswaran, H., (2000). Oxisoils. Adv. Agron., 68,151195.

Callère, S.; Henin, S.; Rautureau, M., (1982). Minéralogie des argiles: Tome 1 . Structure et propriétés physico-chimiques, Ed. Masson Tome 1, Milan.

Callère, S.; Henin, S.; Rautureau, M., (1989). Les argiles, Ed SEPTINA, Paris.

Castelein, O., (2000). Influence de la vitesse du traitement thermique sur le comportement d'un kaolin: application au frittage rapide, thèse de Doctorat de l'université de limoges.

Chung, F. H., (1991). Unified theory and guidelines on adhesion. J. Appl. Polym. Sci., 42, 1319-1331.

Gimsing, A. L.; Szilas, C.; Borggaard, O. K., (2007). Sorption of glyphosate and phosphate by variable-charge tropical soils from Tanzania, Geoderma, 138(1-2), 127-132.

Fardeau J. C.; Zapata, F., (2002). Phosphorus fertility recapitalisation of nutrient depleted tropical acid soil with reactive phosphate rock: An assessment using the isotopic exchange technique. Nutr. Cycl. Agroeco., 63, 69-79.

Holtzapffel, T., (1985). Les minéraux argileux: préparation, analyse diffractométrique et détermination; Société Géologique du Nord, 12, 136.

Martinez, M., (2001). Caractérisation acido-Basique des Surfaces: Application à l'adhésion, Probatoire C.N.A.M.

Memotec (2004). L'élimination du phosphore présent dans les eaux résiduaires urbaines, 23, 3 .

Mollé, (2004). Rétention du phosphore sur matériau défini, thèse partie $C, 25-35$.

Nuray, S., (1999). Heavy metal removal from aquatic systems by northern anatolian smectites. Publication. Département de chimie de l'Université D'Ankara, Turquie, 1-6.

Özacar, M.; Sengil, I. A., (2003). Enhancing phosphate removal from wastewater by using polyelectrolytes and clay injection. J. Hazard. Mater., 100(1), 131-146.

Parfitt, R. L., (1978). Anion adsorption by soils and soils materials. Adv. Agron., 30, 1-49.

Violante, A.; Pigna, M.; Ricciardella, M.; Gianfreda, L., (2002). Adsorption of phosphate on variable charge minerals and soils as affected by organic and inorganic ligands. 28(1), 279-295.

Yeh, S. H.; Wan, C. C., (1994). Co deposition of SiC particles with nickel in a WATT bath. J. Appl. Electrochem., 24, 993-1000. 


\section{AUTHOR (S) BIOSKETCHES}

Dable, P. J. M. R., M.Sc., Ph.D. in materials sciences, associate professor in the Polytechnic National Institute Houphouët-Boigny of Yamoussoukro, Ivory Coast, Email: pjmardable@yahoo.com

Adjoumani, Y. J., M.Sc. student in Industrial Process, Synthesis and Environmental Laboratory, Polytechnic National Institute Houphouet-Boigny of Yamoussoukro, Ivory Coast, Email: yjadjoumani@yahoo.fr

Yao, B., M.Sc., Ph.D. in industrial science, professor in the Polytechnic National Institute Houphouët-Boigny of Yamoussoukro, Ivory Coast, Chief of the Industrial Process, Synthesis and Environmental Laboratory, Email:beyao@yahoo.fr

Ado, G., M.Sc., Ph.D. in materials science, professor, head manager of the Polytechnic National Institute Houphouët-Boigny of Yamoussoukro, Ivory Coast, Email: adogossan@yahoo.fr

This article should be referenced as follows:

Dable, P. J. M. R.; Adjoumani, Y. J.; Yao, B.; Ado, G., (2008). Wastewater dephosphorization using crude clays. Int. J. Environ. Sci. Tech., 5(1), 35-42. 